\title{
RELAÇÕES DE SIGNIFICAÇÃO NAS UNIDADES TERMINOLÓGICAS DA PERIODONTIA
}

\author{
Leda Cecilia Szabo*
}

\begin{abstract}
RESUMO: Este trabalho tem como objetivo descrever e analisar as relações de significação nas unidades terminológicas da Periodontia numa abordagem bilíngüe: inglês-português. Os resultados da análise revelaram que elas compartilham, com as unidades lexicais da língua comum, muitas caracteristicas e que as eventuais diferenças entre elas devem-se principalmente à ação prescritiva exercida pelas organizações científicas e profissionais.
\end{abstract}

UNITERMOS: Terminologia; Periodontia; vocabulário; unidade terminológica.

ABSTRACT: This paper aims at describing and analyzing the meaning relationship involving the terminological units of Periodontology by using a bilingual approach: English - Portuguese. The results of the analysis showed that they share many features with the lexical units of common language and that the eventual differences found are mainly due to the prescriptive rules imposed by the professional and scientific organizations.

KEYWORDS: Terminology; Periodontology; vocabulary; terminological unit.

\section{Introdução}

Este artigo tem como objetivo apresentar as relações de significação encontradas no vocabulário da Periodontia, produto dos resultados obtidos em uma investigação realizada no quadro de nossa Tese de Doutorado, cujo objetivo foi o de descrever

* Doutora em Lingüística pela Universidade de São Paulo. Professora da Universidade Metodista de São Paulo. 
e analisar as unidades terminológicas dessa subárea da Odontologia. Tais unidades terminológicas foram analisadas no ambiente textual-discursivo, como elementos da comunicação humana. Essa abordagem vai ao encontro de uma linha teórica da Terminologia que se ocupa do termo como unidade lingüísticopragmática, procurando compreendê-lo numa perspectiva mais ampla que a delineada pelas visões teóricas mais tradicionais.

Segundo Krieger (2001),

buscar novos parâmetros explicativos para a apreensão do engendramento das terminologias, intentando identificar as configurações que assumem nos distintos universos de discurso para examiná-las comparativamente, é uma forma de favorecer as atividades de Terminografia, mas, sobretudo, de demonstrar o alcance teórico-metodológico da Terminologia, alicerçado, hoje, em novas bases epistemológicas.

Foram, assim, descritas e analisadas 750 unidades terminológicas numa perspectiva bilíngüe (inglês e português). Essa investigação insere-se na linha de pesquisa "Análise do Léxico: Lexicologia e Terminologia", coordenada pela Profa. Dra. Maria Aparecida Barbosa, da Universidade de São Paulo, integrando o projeto "Natureza, funções, tipologia e condições de produção de dicionários terminológicos e dicionários especializados".

\section{As relações de significação}

As relações de significação são as que se estabelecem entre o significante e o significado. O quadro a seguir, idealizado por Barbosa (1998: 19), apresenta essas relações. 


\begin{tabular}{|c|c|c|}
\hline Significado (Contéudo) & Significante (Expressão) & \\
\hline & & $\begin{array}{l}\text { 1. Monossemia: a um elemento do conjunto } \\
\text { ste. corresponde um e somente um elemento do } \\
\text { conjunto sdo. }\end{array}$ \\
\hline & & $\begin{array}{l}\text { 2. Polissemia propriamente dita: a um elemento } \\
\text { do conj. ste. correspondem dois ou mais } \\
\text { elementos do conj. sdo., estes em relação de } \\
\text { oposição transitiva. }\end{array}$ \\
\hline & & $\begin{array}{l}\text { 3. Homonímia: a um elemento do conj. ste. } \\
\text { correspondem dois ou mais elementos do conj. } \\
\text { sdo., estes em relação de oposição disjuntiva. }\end{array}$ \\
\hline & & $\begin{array}{l}\text { 4. Homossemia total (= sinonímia): a dois ou } \\
\text { mais elementos do conj. ste. corresponde um e } \\
\text { somente um elemento do conj. sdo. }\end{array}$ \\
\hline & & $\begin{array}{l}\text { 5. Homossemia parcial (= parassinonímia): a } \\
\text { dois ou mais elementos do conj. ste.. } \\
\text { correspondem dois ou mais elementos do conj. } \\
\text { sdo., estes em relação de oposição transitiva. }\end{array}$ \\
\hline & & $\begin{array}{l}\text { 6. Hiperonímia/hiponímia: a dois elem. do } \\
\text { conj. ste., em relação de oposição disjuntiva, } \\
\text { correspondem dois ou mais elem. do conj. sdo., } \\
\text { estes em relação de oposição transitiva, co- } \\
\text { hipônimos, todos subordinados a um sdo. mais } \\
\text { extensivo. }\end{array}$ \\
\hline & & $\begin{array}{l}\text { 7. Paronímia: a dois elem. do conj. ste., em } \\
\text { relação de oposição transitiva, correspondem } \\
\text { dois elem. do conj. sdo., estes em relação de } \\
\text { oposição disjuntiva ou transitiva. }\end{array}$ \\
\hline
\end{tabular}

\section{1. Monossemia, homonimia, polissemia}

Em áreas e subáreas de terminologia controlada como as que pertencem à grande área das Ciências da Saúde, é de se esperar que a constituição do vocabulário obedeça a padrões rígidos, de modo a favorecer a monossemia e, conseqüentemente, evitar a polissemia e a homonímia. A observação dos termos da Periodontia não revelou homonímia no vocabulário dessa linguagem especializada. Por outro lado, encontram-se, no vocabulário da Periodontia, alguns termos polissêmicos, embora em pequeno número. Geralmente envolvem um processo metonímico 
de uso da designação de um conceito concreto para também nomear o conceito abstrato, como demonstram os textos a seguir, em que se utiliza a mesma designação tanto para o tecido como para a técnica, ou o procedimento em que esse tecido é manipulado.

Various techniques for root coverage have been described. The most desirable technique is the free gingival graft [...] When a free graft is placed over an avascular surface, its survival is dependent on nutrition and hydration from peripheral tissues. (Michael ides; Wilson, 1994, 121). ${ }^{1}$ (grifos meus)

Essa transferência se dá devido a uma relação semântica muito próxima entre o material utilizado em determinado procedimento cirúrgico e o próprio procedimento, de forma que o mesmo termo passa a designar ambos os conceitos.

Outro tipo de polissemia, de origem diversa da ocasionada por analogia entre dois conceitos, é a que encontramos em ocorrências como oral epithelium ("epitélio oral"), que, na linguagem especializada da Periodontia, pode significar: (1) "epitélio que reveste a cavidade oral", (2) "parte do epitélio gengival que reveste a superficie externa da gengiva". A origem dos dois significados para o mesmo significante está no fato de que, para a acepção (2), o termo completo (e, conseqüentemente, mais transparente) é oral epithelium of the gingiva ("epitélio oral da gengiva"), o qual, nos textos da Periodontia, costuma ser abreviado para oral epithelium ("epitélio oral"). O encurtamento de um sintagma longo agiliza o processo de comunicação, mas torna o termo menos transparente. Quando a forma coincide com a designação de outro conceito dentro da área do conhecimento, ocorre a polissemia, de modo que o recurso utilizado para favorecer a comunicação acaba, em teoria, por prejudicá-la, pois dá origem a um duplo sentido. Na prática, porém, a ambigüidade se desfaz no nível do contexto.

\footnotetext{
1 Várias técnicas de recobrimento radicular têm sido descritas. A melhor é o "enxerto gengival livre" [...] Quando um "enxerto livre" é colocado sobre uma superficie avascular, sua sobrevivência depende da nutrição e hidratação provenientes dos tecidos periféricos.
} 


\subsection{Homossemia}

As diferentes situações de uso, ligadas a condições geográficas, sociais, temporais etc., e as condições lingüísticas, quer no nível fonológico, gráfico, morfológico, lexical ou sintático, favorecem a ocorrência de várias denominações para o mesmo conceito ou conceitos semelhantes. Porém, ao contrário do que ocorre na língua comum, na Terminologia de caráter prescritivo tal diversidade de denominações é controlada pelos especialistas, que elegem os termos preferenciais e desautorizam os que poderiam prejudicar a clareza da comunicação especializada. Apesar desse cuidado, entretanto, o vocabulário da Periodontia apresenta grande variedade de formas para o mesmo conceito ou para conceitos assemelhados.

Para descrever as relações de homossemia no vocabulário da Periodontia, foram considerados três aspectos: o significante, o significado e o registro. Assim, procurou-se responder às seguintes indagações:

1. Os significantes correspondem a um mesmo significado ou a significados semelhantes?

2. Os elementos do conjunto significante estão em relação de oposição transitiva ou disjuntiva?

3. Os termos são comutáveis em todos os contextos?

O quadro a seguir, inspirado no de Barbosa (1998), sintetiza os resultados encontrados. 
Homossemia no vocabulário da Periodontia

\begin{tabular}{|c|c|c|c|}
\hline Significado & Significante & \begin{tabular}{l}
\multicolumn{1}{c}{ Registro } \\
Os termos são comutá- \\
veis em todos os com- \\
textos? \\
Sim (S) / Não (N) \\
\end{tabular} & Exemplos \\
\hline & & S & $\begin{array}{l}\text { alveolar bone proper / } \\
\text { cribriform plate } \\
\text { osso alveolar } \\
\text { propriamente dito / } \\
\text { lâmina cribriforme }\end{array}$ \\
\hline & & $\mathrm{S}$ & $\begin{array}{l}\text { osseous defect / bone } \\
\text { defect/ bony defect } \\
\text { gengiva interdentál / } \\
\text { gengiva interdentária }\end{array}$ \\
\hline & & $\mathrm{N}$ & $\begin{array}{l}\text { Collagen fiber/ } \\
\text { collagen fibre }\end{array}$ \\
\hline & & $\mathrm{N}$ & $\begin{array}{l}\text { gingiva / gum } \\
\text { periodontitis/ pyorrhea } \\
\text { periodontite/ piorréia }\end{array}$ \\
\hline
\end{tabular}

No vocabulário da Periodontia, foi muito rara a ocorrência de homossemia total, entendendo-se por "homossemia total" o tipo de relação de significado em que a um - e somente um elemento do conjunto significado correspondem dois ou mais elementos do conjunto significante, em oposição disjuntiva, o que vai ao encontro do que diz Barros (2004a: 221), que considera esse tipo de relação "muito raro, já que normalmente as unidades lexicais não são permutáveis em todos os contextos, não têm a mesma distribuição, nem os mesmos sentidos cognitivos e afetivos". Ocorreu, no entanto, com bastante freqüência o tipo de relação homossêmica em que a um único elemento do conjunto significado correspondem dois ou mais elementos do conjunto significante, em oposição transitiva, apresentando alternância em algum nível lingüístico, a saber: 
1. Alternância morfológica: "gengiva interdentária" / "gengiva interdental"; bony defect / bone defect.

2. Alternância lexical entre uma composição erudita (constituída apenas de elementos greco-latinos) e uma composição híbrida (formada por elementos greco-latinos e elementos vernáculos; estes, no caso do inglês, de base germânica): osseous defect / bone defect.

3. Alternância lexical entre um dos elementos da composição: toothbrush trauma / toothbrush injury.

4. Alternância entre um termo complexo em sua forma expandida e as formas em que um dos elementos da composição foi omitido, bem como delas entre si: bacterial dental plaque / dental plaque / bacterial plaque / plaque: "placa dental bacteriana" / "placa dental" / "placa bacteriana" / "placa", periodontal ligament space / periodontal space: "espaço do ligamento periodontal" / "espaço periodontal".

5. Alternância entre a forma expandida e a sigla: guided tissue regeneration / GTR: "regeneração tecidual guiada" / "RTG".

6. Alternância gráfica: osteoectomy / ostectomy / osteotomy: "osteoectomia" / "ostectomia" / "osteotomia".

As alternâncias morfológicas costumam estar relacionadas às opções de derivação e composição de que cada língua dispõe. As formas expandidas são mais transparentes, ao passo que as abreviadas agilizam o processo de comunicação. Já as variações gráficas freqüentemente indicam várias fases de integração dos elementos de uma composição.

As condições de homossemia parcial, isto é, aquelas em que não há comutação em todos os contextos, costumam relacionar-se a (1) diferentes niveis discursivos, (2) modificações conceituais ao longo do tempo, (3) diferenças regionais:

1. Termo usado nas comunicações de caráter técnico-científico x palavra usada na comunicação com o público: gingiva $x$ gum.

2. Termo designativo de um conceito ultrapassado $\mathrm{x}$ termo relacionado a uma reformulação do esquema conceitual: pyorrhea $x$ periodontitis ("piorréia" x "periodontite"). Nesse caso, 
o termo designativo do conceito ultrapassado é descartado, e seu uso, desautorizado na linguagem especializada.

3. Variação gráfica e distribuição complementar no nível geográfico: fiber (grafia americana) $x$ fibre (grafia inglesa). As duas formas correspondem ao mesmo conceito, mas não são comutáveis em todos os contextos devido às especificidades de uso local.

Nos casos acima, as formas apresentam-se em distribuição complementar. Vale observar que aquelas que se referem a esquemas conceituais de caracterização popular, bem como as que designam conceitos ultrapassados, são postas à margem do sistema conceitual; daí decorre que esses parassinônimos não são considerados na Terminologia de caráter prescritivo, uma vez que, dentro desta visão, o conceito deve ocupar um lugar definido no sistema hierárquico.

\subsection{Hiperonimia, hiponimia, co-hiponimia}

As relações de hiperonímia e hiponímia são muito importantes na Terminologia de caráter prescritivo, uma vez que os conceitos e termos organizam-se numa estrutura hierarquizada. Espera-se, inclusive, que a estrutura morfossintática dos hiperônimos, hipônimos e co-hipônimos reflita as relações conceituais, o que não é necessariamente a regra na língua comum. A estrutura morfossintática das unidades terminológicas que compõem o vocabulário da Periodontia reflete a posição que cada termo ocupa no sistema hierárquico, de forma que, na estrutura do hipônimo, o hiperônimo compõe o núcleo do sintagma nominal (nos casos de termos compostos) ou o radical do termo simples.

\begin{tabular}{|l|l|}
\hline \multicolumn{1}{|c|}{ Hiperônimos } & \multicolumn{1}{c|}{ Hipônimos } \\
\hline gingiva & $\begin{array}{l}\text { attached gingiva } \\
\text { free gingiva }\end{array}$ \\
\hline furcation & $\begin{array}{l}\text { bifurcation } \\
\text { trifurcation }\end{array}$ \\
\hline
\end{tabular}

TradTerm, 12, 2006, p. 293-307 
Quando o hiperônimo já é um termo composto, evita-se que o hipônimo se transforme numa longa seqüência nominal, com três ou mais radicais, através da supressão do(s) elemento(s) não nuclear(es) da composição, para que o núcleo, assim destituído, receba os determinantes que atendam à caracterização do conceito designado pelo termo hipônimo.

\begin{tabular}{|l|l|}
\hline \multicolumn{1}{|c|}{ Hiperônimos } & \multicolumn{1}{c|}{ Hipônimos } \\
\hline dental calculus $>$ calculus & $\begin{array}{l}\text { supragingival } \text { calculus } \\
\text { subgingival } \underline{\text { calculus }}\end{array}$ \\
\hline toothbrush $>$ brush & interdental $\underline{\text { brush }}$ \\
\hline
\end{tabular}

Os co-hipônimos, subordinados aos hiperônimos, ocupam, na estrutura hierárquica, a mesma posição. A relação vertical com o hiperônimo (relação de subordinação) evidencia-se na estrutura morfológica, como vimos, através da adoção do mesmo núcleo. O elemento não nuclear da composição, por sua vez, designa a característica distintiva. Assim, a "periodontite crônica" e a "periodontite agressiva" são tipos de "periodontite" que se distinguem pela velocidade de progressão e pelo grau de agressividade; a "gengiva interdentária" e a "gengiva marginal" são porções da "gengiva" que se distinguem por sua localização. Vale lembrar que os traços distintivos não são intrínsecos ao objeto, mas derivam da análise dos dados da experiência, em que o estabelecimento de relações diversas permite estruturá-los num sistema mais ou menos coerente, dentro do processo histórico da constituição do conhecimento na área específica do saber ou da atuação profissional.

Na Periodontia, as relações estabelecidas no nível conceitual e as características que distinguem um conceito de outro no mesmo nível hierárquico refletem-se, pois, na estrutura morfossintática dos termos co-hipônimos, de modo a se encontrar uma correspondência entre seus elementos constituintes, suas características distintivas e as relações conceituais, como se pode notar no quadro a seguir. 


\section{Relações conceituais e estruturas morfossintáticas dos co-hipônimos}

\begin{tabular}{|c|c|}
\hline Tipo de relação / traço distintivo & Exemplos \\
\hline $\begin{array}{l}\text { Causal (derivada da associação entre } \\
\text { causa e efeito) }\end{array}$ & $\begin{array}{l}\text { diabetes-associated gingivitis / pregnancy- } \\
\text { associated gingivitis } \\
\text { "gengivite associada ao diabete" / "gengivite } \\
\text { associada à gravidez" }\end{array}$ \\
\hline $\begin{array}{l}\text { Espacial (derivada da tentativa de } \\
\text { localização, a partir das estruturas } \\
\text { dentárias) }\end{array}$ & \\
\hline Acima / abaixo da linha gengival & $\begin{array}{l}\text { supragingival biofilm / subgingival biofilm } \\
\text { "biofilme supragengival" / "biofilme } \\
\text { subgengival" }\end{array}$ \\
\hline $\begin{array}{l}\text { Em direção ao ápice (raiz) } x \text { em } \\
\text { direção à coroa }\end{array}$ & $\begin{array}{l}\text { apically positioned flap / coronally positioned } \\
\text { flap } \\
\text { "retalho posicionado apicalmente / retalho } \\
\text { posicionado coronariamente" }\end{array}$ \\
\hline $\begin{array}{l}\text { Em posição horizontal / em posição } \\
\text { vertical }\end{array}$ & $\begin{array}{l}\text { horizontal bone loss / vertical bone loss } \\
\text { "perda óssea horizontal" / "perda óssea } \\
\text { vertical" }\end{array}$ \\
\hline $\begin{array}{l}\text { De composição (derivada da } \\
\text { necessidade de se conhecer a } \\
\text { constituição de um tecido ou órgão) }\end{array}$ & $\begin{array}{l}\text { acellular cementum / cellular cementum } \\
\text { "cemento acelular" / "cemento celular" }\end{array}$ \\
\hline $\begin{array}{l}\text { De gradação (derivada da tentativa } \\
\text { de medir a distância entre a condição } \\
\text { saudável e a patológica) }\end{array}$ & $\begin{array}{l}\text { class I furcation defect / class II furcation defect } \\
\text { / class III furcation defect } \\
\text { "defeito de furca (de) classe I" / "defeito de } \\
\text { furca (de) classe II" / "defeito de furca (de) } \\
\text { classe III" }\end{array}$ \\
\hline
\end{tabular}




\subsection{Paronimia}

Como nos mostra o quadro de Barbosa, a paronímia ocorre quando a dois elementos do conjunto significante, em relação de oposição transitiva, correspondem dois elementos do conjunto significado, estes em relação de oposição disjuntiva ou transitiva. No vocabulário da Periodontia, o único caso a destacar é o da semelhança fonética e gráfica que ocorre, em português, entre "cemento" e "cimento". "Cemento" designa o tecido conjuntivo mineralizado, interligado com as fibras do ligamento periodontal, que recobre as superficies radiculares e, ocasionalmente, pequenas porções das coroas dos dentes; ao passo que "cimento" ou "cimento cirúrgico" é a denominação do curativo utilizado sobre uma ferida cirúrgica para protegê-la durante o processo de cicatrização. Comum aos dois termos está a origem latina: caementum. Em inglês, o termo equivalente a "cemento" é cementum, ao passo que o termo que corresponde a "cimento" (periodontal) é (periodontal) dressing ou (periodontal) pack. Assim, não ocorre a paronímia, em inglês, no domínio da Periodontia, embora o termo cement seja usado, na Medicina e na Odontologia, para designar o material utilizado em cirurgias para preencher, colar ou bloquear.

\subsection{O caso dos epônimos}

Nas Ciências da Saúde, a eponímia consiste na utilização de um nome próprio para designar uma estrutura anatômica, uma doença ou condição patológica, um procedimento ou método terapêutico. Geralmente o epônimo advém da homenagem a quem descobriu ou primeiro descreveu a estrutura, doença ou o procedimento nomeado.

No vocabulário da Periodontia, dentre os 750 termos pesquisados, foram encontrados 14 epônimos. O fato de não serem muito numerosos os casos de eponímia na Periodontia deve-se, provavelmente ao fato de que a utilização dos epônimos contraria dois dos princípios recomendados para a formação de termos, preconizados pela Norma ISO 704: o da consistência, que prescreve que os termos se integrem no sistema conceitual e 
sejam coerentes com ele, e o da adequação, que recomenda que a denominação não induza a erros ou confusões. O princípio da adequação, por sua vez, baseia-se numa relação que se procura estabelecer entre o significado de uma unidade terminológica (cuja caracterização é controlada para evitar a imprecisão denominativa) e o significante (cujos elementos morfológicos devem ser coerentes com a caracterização atribuída). Nesse contexto, o sentido etimológico não só da unidade terminológica como um todo, bem como de seus elementos constituintes, adquire importância maior que na linguagem não especializada, pois se espera que a decodificação literal dos formantes de um termo reflita seu significado. Como a origem do epônimo está na homenagem ou alusão a uma pessoa, essa "motivação" da unidade terminológica fica prejudicada.

$\mathrm{Na}$ área médica, os projetos de harmonização terminológica como a Nomenclatura Anatômica (Nomina Anatomica) e a Nomenclatura Internacional de Doenças (International Nomenclature of Diseases) desautorizam o uso de epônimos. A Nomina Anatomica determina a criação de termos cuja composição morfológica indique a forma da estrutura anatômica, sua posição ou situação, trajeto, conexões ou inter-relações, relação com o esqueleto ou sua função. A International Nomenclature of Diseases prescreve que haja um único nome para cada doença e que a escolha da designação se fundamente essencialmente na etiologia e patogenia das doenças (Barros, 2004b). De acordo com esses critérios, foram abolidos, pelo menos em teoria, os epônimos, exceto os consagrados pelo uso. ${ }^{2}$ Entretanto há os que, embora não defendendo o uso indiscriminado dos epônimos, advoguem que não sejam banidos das nomenclaturas científicas, uma vez que trazem em si um pouco da história da ciência.

Guardadas as devidas proporções, parecem valer para o caso dos epônimos as reflexões feitas por Dick (1998) sobre o significado dos nomes próprios na Onomástica, que, segundo a

\footnotetext{
2 "Durante sessenta anos, as revisões ulteriores da Nomenclatura persistiram na eliminação dos nomes próprios; mas, em 1998, a nova Terminologia Anatômica reincorporou, em lista separada, uma série de epônimos clássicos que ainda são largamente utilizados em textos médicos." (Fernandes, 2005).
} 
autora, deve ser considerado num contexto mais amplo que o etimológico:

Procuramos, para isso, alcançar o nomeador/emissor ou o agente do processo de nomeação, no ato enunciativo. Situam-se aqui duas circularidades cronológicas, em que o tempo cultural ou coletivo vai se contrapor, complementando, ao tempo biológico ou particular do individuo, somatória de todas as suas experiências, projetadas simbolicamente em um enunciado ou em um sintagma onomástico. (Dick, 1998: 46)

\section{As unidades terminológicas como signos lingüisticos}

Vimos que, apesar do fato de o vocabulário da Periodontia ser controlado pelas sociedades científicas e profissionais, controle esse evidenciado principalmente na estrutura morfológica dos termos hiperônimos, hipônimos e co-hipônimos, na harmonização internacional, marcada pela preferência pelos morfemas greco-latinos, e na busca do ideal da monossemia, as unidades terminológicas da Periodontia são também caracterizadas por relações não tão almejadas, como a homossemia, a polissemia, bem como a eponímia.

A análise das características das relações homossêmicas revelou que, quando dois ou mais significantes correspondem ao mesmo significado em todos os contextos, há uma oposição transitiva entre os elementos que compõem a estrutura morfológica dos significantes, o que, de certa forma, parece amenizar a confusão que poderia advir da profusão de significantes para um só significado, pois há, entre eles, um elemento comum. Quanto aos parassinônimos de registro popular e as designações de conceitos considerados ultrapassados no âmbito da área do saber, o controle exercido pelas sociedades científicas e profissionais evita que sejam usados nas comunicações de caráter técnico-científico. Em teoria, mais danosa à comunicação unívoca seria a polissemia, considerando-se que seria inadmissivel, e até mesmo perigosa, no discurso especializado, a utilização de um significante com vários significados. Entretanto, foram poucos 
os casos de polissemia registrados no vocabulário da Periodontia, e a possivel ambigüidade desfaz-se no contexto. Também não foram numerosas as ocorrências de epônimos, pois parece haver, atualmente, na Odontologia e suas subáreas, à semelhança do que acontece também na área médica, uma tendência a evitálos, exceto nos casos já consagrados pelo uso. Pode-se dizer que, apesar da variedade das relações entre significado e significante, principalmente relações de homossemia, a comunicação especializada não parece sofrer danos importantes, embora isso não implique dizer que tal variedade não incomode os periodontistas, que, como os demais profissionais da saúde, preocupamse com a harmonização terminológica.

\section{Conclusão}

A observação das relações de significação das unidades terminológicas da Periodontia permite-nos constatar que elas compartilham as características das demais unidades lexicais. O comportamento diferenciado, mormente no que se refere à menor incidência de polissemia e a uma certa "consciência denominativa que torna a arbitrariedade do signo lingüistico mais tênue" (Krieger, 2001) que na língua geral, deve-se, ao que parece, ao controle externo, exercido pelas associações científicas e profissionais, e não a fatores relacionados à natureza intrínseca das terminologias científicas. Portanto, dessa descrição e análise do vocabulário da Periodontia pode-se concluir que os termos, ou unidades terminológicas, ou, ainda, unidades de comunicação especializada (Cabré, 1999) são signos terminológicos com características formais e comportamentais semelhantes às das palavras da língua comum. Como sofrem um controle externo, que procura reduzir a polissemia ao nivel menos prejudicial possivel à segurança e precisão da comunicação especializada (embora tolere a homossemia derivada da alternância de elementos lingüísticos, desde que se preserve a mesma caracterização conceitual), apresentam menor riqueza de relações de significação que os signos das linguagens não marcadas e uma predominância de termos formados pelo processo de composi- 
ção, uma vez que esse tipo de formação favorece o princípio da transparência, que, com a "monossemia" e a harmonização internacional, se constitui no ideal - almejado, mas nunca plenamente atingido - da Terminologia prescritiva.

\section{Referências bibliográficas}

BARBOSA, Maria Aparecida. (1998) Relações de significação nas unidades lexicais. In: CARVALHO, Nelly Medeiros de \& SILVA, Maria Emília Barcellos da. (orgs.) (1998) Anais do $1^{\circ}$ Encontro Nacional do GT de Lexicologia, Lexicografia e Terminologia da ANPOLL. Recife, p. $19-40$.

BARROS, Lídia Almeida. (2004a) Curso básico de Terminologia. São Paulo: Edusp.

. Processos clássicos e atuais da internacionalização da terminologia médica. Disponível em: <www.gel.org.br/4publica-estudos2004>. Acesso em: 21 abr. 2005.

CABRÉ, Maria Teresa. (1999) La terminología: representación y comunicación. Barcelona: IULA.

DICK, Maria Vicentina de Paula do Amaral. (1998) A significação hiponímica e hiperonímica nas práticas onomásticas. In: CARVALHO, Nelly Medeiros de \& SILVA, Maria Emília Barcellos da. (orgs.) Anais do $1^{\circ}$ Encontro Nacional do GT de Lexicologia, Lexicografia e Terminologia da ANPOLL. Recife, p. 41-59.

FERNANDES, Geraldo José Medeiros. Epônimos em Anatomia: sim ou não? Disponível em: <www.sbanatomia.com.br/editorial21.htm>. Acesso em 21 abr. 2005.

INTERNATIONAL ORGANIZATION FOR STANDARDIZATION. (2000) ISO 704: terminology work - principles and methods. Genève.

KRIEGER, Maria da Graça. (2001) O termo: questionamentos e configurações. TradTerm v. 7. Faculdade de Filosofia, Letras e Ciências Humanas, Universidade de São Paulo. São Paulo: Humanitas. p. 111-140. 